\title{
Closing the circle: an agroecological response to covid-19
}

\author{
Barbara Gemmill-Herren ${ }^{1}$
}

Accepted: 25 April 2020 / Published online: 14 May 2020

(c) Springer Nature B.V. 2020

Over time, the food systems of the world have become highly globalized (and regionalized), with food often grown in one country or region, shipped to another for processing, and then shipped on (or back) for sale. Little thought is given to the implications of this, until a time of crisis, such as the current Covid-19 pandemic. At moments like this, we realize how shortsighted our policies are and how brittle our food supply chains can be. There is, however, a tremendous scope for responding to this crisis through building more sustainable, equitable food systems with policies that support localized supply chains, creating circular economies that benefit people and the planet.

Many of the initial food-related responses to the pandemic in the United States have been, indeed, measures to bring food production and supply chains closer and more under the agency of people. Farmers markets in a number of states (California and Minnesota, for example) have been declared essential businesses and made exempt from closure. Community-supported agriculture schemes are suddenly extremely popular and even over-subscribed. There is a renewed interest in home gardening, with calls for people and communities to grow as much as they can to provide themselves and their communities with healthy fresh food. There is an unprecedented surge in demand for local food in many countries of Europe and North America as people have recognized how powerless they are when items disappear from supermarket shelves.

However, these are all measures that are the prerogative of those with resources at hand. The deep injustices of

Project team member, Committee on World Food Security of the UN, High-Level Panel of Experts Report on "Agroecological and other innovative approaches for sustainable agriculture and food systems that enhance food security and nutrition"

This article is part of the Topical Collection: Agriculture, Food \& Covid-19

Barbara Gemmill-Herren

b.gemmillherren@prescott.edu

1 Prescott College, Prescott, AZ, USA unilaterally closing down economies without giving consideration to the needs of all citizens is becoming increasingly apparent. Widespread protests are breaking out in a number of developing countries, as governments close down transportation routes and food markets that serve urban populations- taking out in the process, a deep and wide swath of the informal economy that supports such food supply channels, and impacting the citizenry that depends upon it.

In Kenya, government policy has been that while agricultural services are essential, and food markets in the capital city of Nairobi can remain open, the highly agricultural counties to the north of Nairobi have agreed to close their markets to be more effective in the stopping the spread of Covid-19. Through an innovative collaborative visual research project (https://medium.com/enabling-sustainabi lity) reports are being posted on peoples' personal experiences and navigation of their new reality under the COVID19 pandemic from Kenya as well as from several other African countries. In Kenya, initial reports are that the disruption of food supply chains is causing a rise in prices in Nairobi and of chaotic struggles of people in informal settlements to acquire food. In addition, the livelihoods of large number of people in the informal economy that both supply food and purchase food through the existing chains are being heavily, and negatively, impacted.

It is time to rethink the underlying construct of calling for more local solutions to food systems and take a broader and longer-term perspective. In this, I would suggest that we look closely at one of the Ten Elements of Agroecology,Circular and solidarity economies ${ }^{1}$ —as adopted by the 194 member countries of the Food and Agriculture Organization of the United Nations (FAO 2018). How genuinely, in both the North and South, can we build the circles in food systems to make them responsive to local needs first, nimble in adapting to disruptions such as the current pandemic, and focused on delivering healthy food to all, as a human right?

\footnotetext{
${ }^{1}$ Circular and solidarity economies that reconnect producers and consumers provide innovative solutions for living within our planetary boundaries while ensuring the social foundation for inclusive and sustainable development.
} 
There are many aspects to this, and just a few that I would mention here. If healthy food as a human right-is taken as the responsibility of the government to protect, they may do so most effectively in investing in food systems based on participation, localness, fairness and justice (HLPE 2019). Specifically addressing the fragility of food systems in the time of a pandemic - but as well the fragility of food systems at any time, I would highlight two areas, among the many others:

- Support for democratically controlled, fairly-governed local infrastructure and transportation channels (treated as public goods along the lines of roads, water and sanitation) to strengthen local and regional food value chains, including respect for the informal (and formal) economies that supply these chains;

- Recognition and support for agroecological, diversified farming systems that provide strong and resilient localized agricultural and food system employment. See, for example, the analysis of Garibaldi and Pérez-Méndez (2019) where countries with higher crop diversity were shown to support more agricultural employment and did not sacrifice socio-economic development or economic growth. Higher crop diversity may require a more diverse set of inputs, logistics, machinery, skills, and services throughout the year ("employment niches"). Moreover, crops can have different processing and commercialization chains. Landscapes with higher crop diversity also provide more resources for other rural economic activities such as beekeeping or tourism, providing a greater number of jobs in rural areas.
The current crisis has exposed, ever more, the cracks in our food and agricultural systems; we can use this as an opportunity to transform these.

\section{References}

FAO. 2018. The 10 elements of agroecology: Guiding the transition to sustainable food and agricultural systems. Rome: FAO.

Garibaldi, Lucas A., and Nestor Pérez-Méndez. 2019. Positive outcomes between crop diversity and agricultural employment worldwide. Ecological Economics 164: 106358.

HLPE. 2019. Agroecological and other innovative approaches for sustainable agriculture and food systems that enhance food security and nutrition. A report by the High Level Panel of Experts on Food Security and Nutrition of the Committee on World Food Security, Rome. https://www.fao.org/3/ca5602en/ca5602en.pdf. Rome: FAO

Publisher's Note Springer Nature remains neutral with regard to jurisdictional claims in published maps and institutional affiliations.

Barbara Gemmill-Herren is an Associate Faculty at Prescott College, Prescott, Arizona, USA and a Senior Associate to the World Agroforestry Centre, supporting the United Nations' work on agroecology and true-cost accounting in agriculture. She was Delivery Manager for Ecosystem Services and Biodiversity at the Food and Agriculture Organization of the United Nations (FAO), responsible for work on Ecosystem Services in Agricultural Production, and Agroecology. She was a project team member of the Committee on World Food Security of the UN, High-Level Panel of Experts Report on "Agroecological and other innovative approaches for sustainable agriculture and food systems that enhance food security and nutrition". 